\title{
AnÁlise estrutural Via METOdologia FEA: ESTUdo DE UM MACACo AUTOMOTIVO CORRELACIONANDO O TESTE FÍSICO DE UM PROTÓTIPO EM LABORATÓRIO E A SIMULAÇÃO VIRTUAL
}

\author{
Evandro Secchi de Oliveira ${ }^{1}$ e Roderley Camargo ${ }^{2}$ \\ ${ }^{1}$ UNISAL Centro Universitário Salesiano de São Paulo \\ ${ }^{2}$ Robert Bosch Ltda
}

E-mails: evandroweg@gmail.com, roderley.camargo@br.bosch.com

\section{RESUMO}

O macaco mecânico é um componente obrigatório nos veículos automotores, e essencial nos momentos em que haja a necessidade de uma intervenção humana, para uma manutenção ou mesmo uma troca de pneu avariado. Tendo como base os aspectos de manufatura, igual importância tem o projeto deste componente, como forma de adequar os requisitos de qualidade, custo e conformidade ambiental, fazendo aderência as diversas normas de segurança humana e ambiental. Neste sentido, apresenta-se neste trabalho um estudo de analise estrutural dos braços de um macaco mecânico, confeccionados em aço estrutural NBR6656-LNE-500 com 2mm de espessura, por meio da metodologia FEA (Finite Element Analyze), obtendo os resultados de deslocamento $(\Delta \mathrm{l})$ e tensão $(\sigma)$, gerado pela carga de $2500 \mathrm{~kg}$ em forma de dados de entrada. Os resultados matemáticos obtidos foram correlacionados com o teste de bancada indicando uma divergência de $1.5 \%$ entre o comportamento do protótipo e a simulação computacional. Assim, validou-se o resultado da análise estrutural e aplicou-se as condições de contorno as modificações de design do produto, tendo em vista que a simulação computacional FEA representa uma condição real de teste.

\section{INTRODUÇÃO}

A análise estrutural via método dos elementos finitos é muito utilizada para validar o design de novos produtos, em sua fase inicial do processo de desenvolvimento do produto (PDP) [1]. Visando acelerar o processo de projeto e orientando os engenheiros a obter um produto com qualidade e com uma perda mínima de material. Objetivando trabalhar com espessuras de chapas cada vez menores, para macacos mecânicos, é necessário utilizar métodos de análise estrutural para acelerar o desenvolvimento e obter um menor custo no desenvolvimento de protótipos. Porém, há que se preocupar com a precisão e a confiabilidade do software escolhido para fazer a análise por elementos finitos, pois os resultados serão comparados com o teste físico. Além disto, esta ferramenta de simulação deve ser robusta o suficiente, para superar com eficiência, as demandas de tempo, custo de projeto e qualidade final da análise FEA [2].

Para obter a solução e ter um parâmetro de referência, foi realizada uma análise FEA com o software CREO Simulate 2.0 para validar os "braços" do macaco tipo sanfona, na condição de $66 \%$ da altura máxima e com uma carga de $2.500 \mathrm{~kg}$. Desta forma, consegue-se representar virtualmente, a severidade de uso deste componente simulando as condições reais. 
A principal motivação para este estudo de análise estrutural, via métodos dos elementos finitos, foi a incerteza inicial dos resultados entre a simulação virtual e o teste de laboratório, relacionado a um macaco mecânico do tipo sanfona. Ao validar o processo de elementos finitos a serem utilizados para gerar a malha ideal para a solução do problema os produtos que possuir as mesmas características de um Macaco Sanfona poderão obter seu design visando otimização de matéria prima sem comprometer a qualidade e obtendo uma redução de custo do produto.

Para iniciar o estudo, foi modelado virtualmente com o auxilio do Software CREO 2.0, um Macaco Sanfona com um design de braço simples, pois o ponto crítico de falha deste tipo de Macaco são os braços, com isso foi confeccionado um protótipo cujos braços foram estampados com aço NBR6656-LNE-500 [3]. O protótipo com todas as características do modelo matemático foi testado em laboratório em uma maquina desenvolvida para realizar a compressão em Macacos Mecânicos, na condição da altura de 66\% da capacidade de altura máxima e $2.500 \mathrm{~kg}$ de carga aplicada. O produto suportou a carga sem demonstrar nenhum sinal visível de deformação plástica nos braços ou qualquer outro componente.

\section{INFORMAÇÔES GERAIS}

Para se desenvolver produtos inovadores e bem-sucedidos no atual cenário global e competitivo, há que ter recursos de informática cientifica e fazer uso de simulação. Neste senso, para que a empresa sobreviva neste ambiente de competição, a simulação deve fazer parte do projeto, já na fase inicial do processo de desenvolvimento do produto [4]. A capacidade de analisar as características multicorpos do desempenho físico de um projeto, antes de criar um primeiro protótipo, pode aumentar de forma significativa a produtividade. As empresas precisam de ferramentas de simulação robustas o suficiente para superar com eficácia as demandas de prazo, custo e qualidade final do produto [5]. A tecnologia de simulação permite a utilização de modelagem matemática, baseada em computador, para aproximar e simular os fenômenos complexos do universo físico, tendo como dados de entrada o modelo CAD 3D [6]. De posse do modelo matemático CAD, que mais caracteriza o produto macaco mecânico, deu-se inicio a análise estrutural via formulação pelo método dos elementos finitos (FEA), dentro do ambiente CAE. Depois das diversas iterações entre os ambientes CAD e CAE, chegou-se a uma solução de design que atendesse aos interesses de projeto, sem contudo prejudicar as exigências de função do produto. Para convalidar os dados teorizados pela analise FEA, iniciou-se a construção de um protótipo físico com as características mais relevantes e observando as condições geométricas providas pelo modelo 3D. Depois, realizou-se um teste pratico de compressão no protótipo recém construído e os resultados práticos foram comparados com a analise estrutural FEA. As conclusões e desdobramentos deste trabalho estão destacados em detalhes no tópico estudo de caso.

\subsection{METODOLOGIA}

A metodologia utilizada foi a aplicação da técnica FEA e posterior comparação com um protótipo físico, construído e testado em laboratório. O espectro da análise e síntese do modelo matemático 3D, será obtido via pacote de simulações do módulo CREO Simulate. Este software de CAE, utiliza modelos digitais 3D para simular fenômenos físicos reais via métodos numéricos convergentes e realizações de cálculos estruturais e seus deslocamentos correlatos. Assim, três etapas complementam este método: Input, Solver e Output [7]. Na fase 
de Input, são considerados os seguintes requisitos: Geometria, Material, Forças aplicadas, Restrições, Propriedades físicas e Elementos. Na fase de Solver, considera-se o critério do método "P", cuja polinomial pode atingir até o $9^{\circ}$. grau. Na fase de Output, considera-se os resultados: Tensão, Deslocamento, Deformação e Tomografia virtual evidenciando as isosurfaces. Neste momento, a intenção é convalidar estes resultados no intervalo de validação da lei de Hooke, especificamente mantendo o componente na região elástica do diagrama "Tensão x Deformação" [8].

Quanto ao delineamento, a metodologia assume uma abordagem orientada ao estudo de caso, em que será demonstrado via projeto de simulação virtual, e confirmado na pratica, por meio da construção material de um macaco mecânico tipo sanfona, como forma de constatação física do que fora teorizado.

\subsection{FUNDAMENTAÇÂO TEÓRICA}

Afim de comprovar a eficácia do aplicativo tridimensional e visando também prever uma possível falha de função, a teoria matemática a ser comprovada é: $E=\sigma / \varepsilon$, no limite da fase elástica, considerando o coeficiente de segurança. A resposta da estrutura as solicitações virtuais, serão expressas em tensões de Von Mises (MPA) e Displacement (mm), seguida de otimização topológica do conjunto formado pelo produto.

A equação da análise estática é [9]:

$$
[\mathbf{K}\}\{\mathbf{u}\}=\{\mathbf{F}\}
$$

Em que,

"K" é a matriz de rigidez do sistema gerada automaticamente pelo CREO Simulate com base na geometria e propriedades aplicadas.

"F" é o vetor de forças aplicadas (o qual é especificado).

"u" é o vetor de deslocamentos que são computados pelo CREO Simulate (elementos de força, tensão, reação, etc.).

\subsection{ARQUITETURA BÁSICA DO MÉTODO DOS ELEMENTOS FINITOS}

A confiabilidade dos resultados obtidos a partir do uso da metodologia FEA, se comparada aos diversos outros métodos empregados nos dias de hoje, se resume na facilidade de interface com o software de analise. O programa de elementos finitos busca na simplificação de operação, uma maneira de adequar os recursos de equações matemáticas e orientá-las ao objeto de analise [10].

Assim, três etapas contemplam uma programação via FEA, como forma de orientação a lógica computacional, quais sejam [11]:

\section{$I N P U T \rightarrow S O L V E R \rightarrow O U T P U T$}

A fase de Input contempla os dados do material e os requisitos do projeto, quais sejam: Geometria, Material, Forças, Restrições e Tipos de elementos. Nesta fase, é de suma importância a representação gráfica da geometria do modelo $\mathrm{CAD}$, com os principais detalhes construtivos, envolvendo a fabricação, montagem e o projeto de fato. Também é importante a entrada dos dados do material a ser utilizado na análise. Faz parte deste tópico: Módulo de elasticidade, Coeficiente de Poisson, Tensão de escoamento, Tensão de Ruptura e Densidade. 
Além disso, a leitura das condições de contorno pode ser feita nesta fase, como também as condições de carregamento são introduzidas nesta etapa. Neste trabalho utilizou-se a formulação de malhas automáticas encapsuladas no método "P", sendo elevado até o $9^{\circ}$. grau do polinômio interpolador [11]. A Figura 1 ilustra a arquitetura do método FEA.

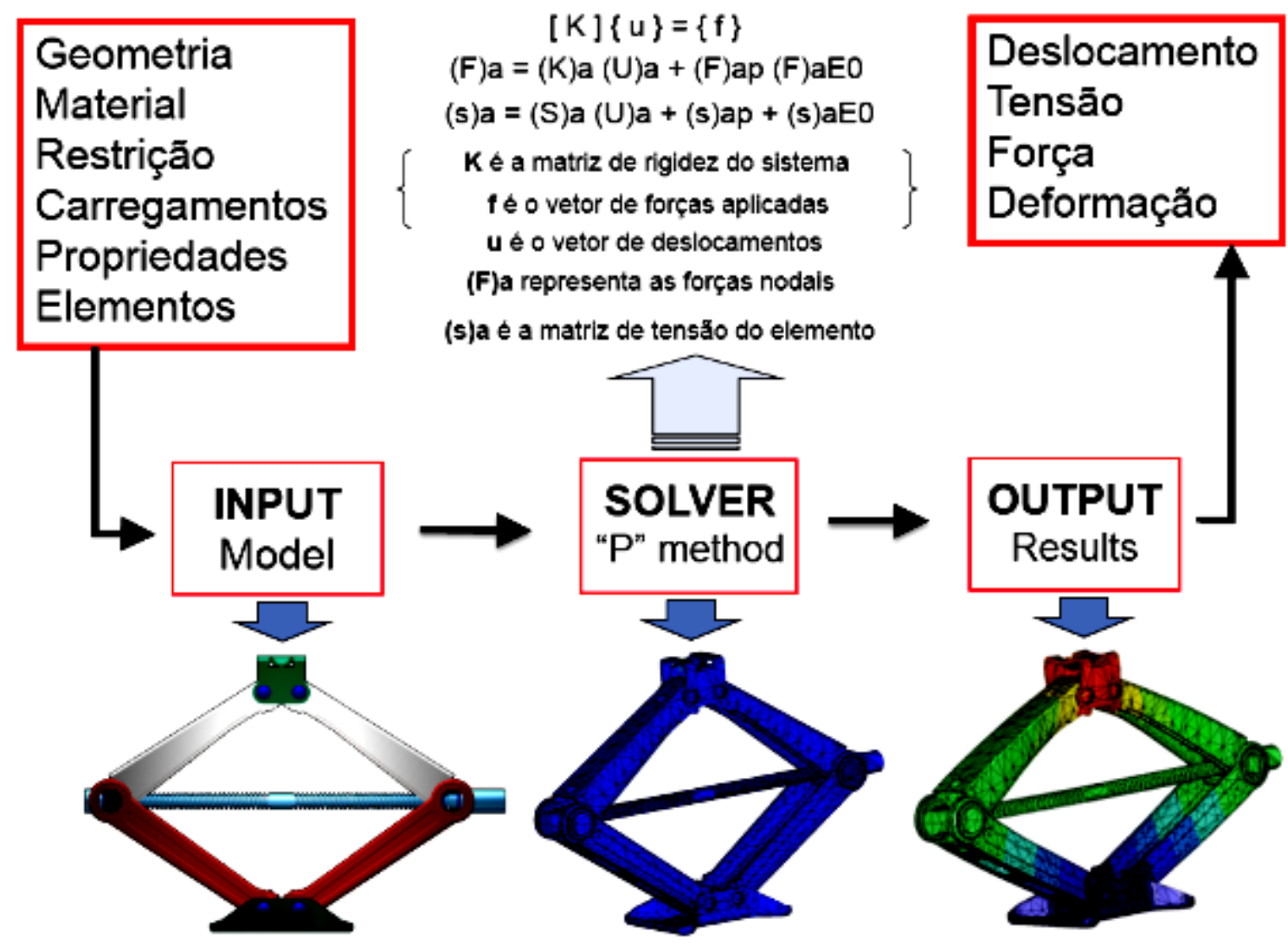

Figura 1 - Arquitetura computacional do método FEA

A fase do Solver diz respeito ao algoritmo computacional que está implementado na rotina de calculo do método. Existem dois tipos de formulações referentes aos tipos de processamentos: Método "P" e Método "H" [10] [9].

No método "H", que é um acrônimo para "height", procura-se discretizar a estrutura, formando um reticulado de nós, cuja somatória forma um elemento. Este elemento tem suas características primarias de sólido de engenharia bem definidas e tecnicamente conhecidas. Assim, quanto mais complexa for a geometria da estrutura, mais refinamento terá de ser feito, visando a construção de uma malha robusta.

No método "P", acrônimo para polinomial, tem-se as equações baseadas no polinômio interpolador, podendo chegar até o $9^{\circ}$. grau. Este polinômio pode atingir a eliminação de Gauss, Lagrange, entre outros [10]. Neste trabalho, optou-se por usar o método "P" com base no algoritmo do aplicativo CREO 2.0 Simulate, por entender-se que a orientação a objeto e a geometria da peça como um todo, gere uma maior confiabilidade de analise.

Na fase de Output, tem-se o resultado da análise estrutural em diversos formatos de saída, de acordo com o critério de falha determinado no escopo da analise estrutural. São 
exemplos de saída de resultados: Tensões, Deformações, Deslocamentos, Gráficos, Diagramas, Temperaturas, Pressões entre outros. A saída gráfica dos resultados, incluindo os aspectos de simulação, dão ao engenheiro analista a noção exata do que está ocorrendo em termos de realidade aumentada, e convergindo para uma solução computacional robusta, no que se refere as condições de entrada [10].

\subsubsection{Definição da técnica de Elementos Finitos}

É uma técnica matemática que consiste em discretizar uma estrutura, - modelo matemático tridimensional - em elementos paramétricos ou isoparamétricos conhecidos e conectados por "nós". As propriedades dos Materiais e Elementos são especificados afim de representarem as propriedades físicas do modelo, conforme ilustrado na Figura 2 [12].

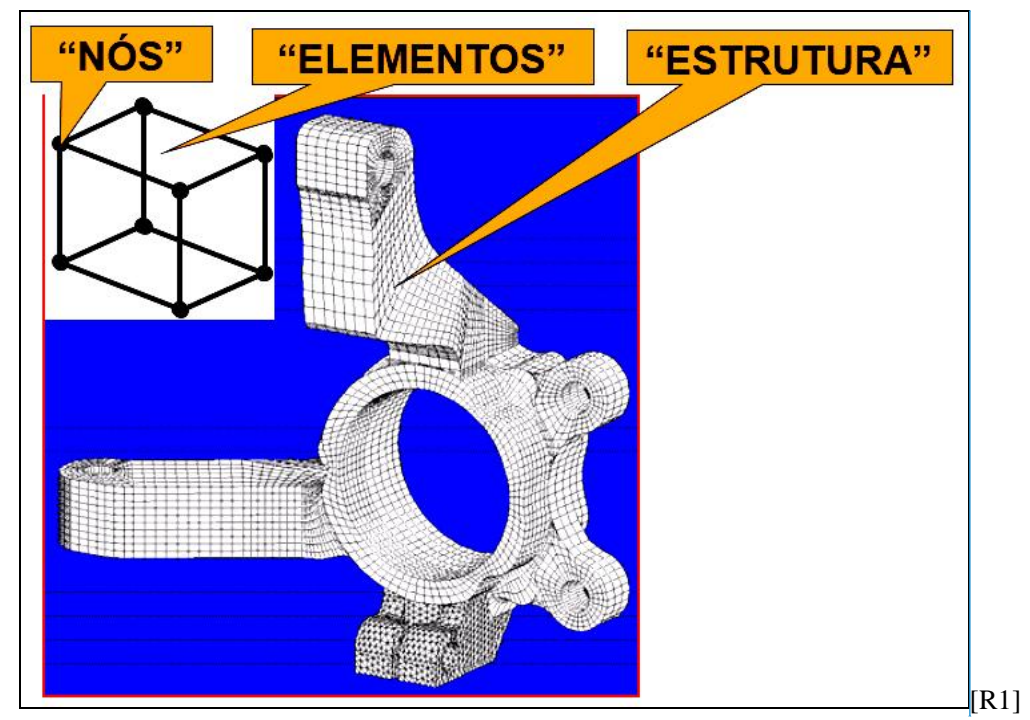

Figura 2 - Definição de estrutura, elementos e "nós"

Também há que se envolver todo o modelo matemático, inserindo as mesmas condições de contorno, consideradas no protótipo, e refinando a malha nos locais em que são mais relevantes, para que o resultado desta análise venha a convergir com o resultado do teste. Ao inserir a localização e a intensidade da carga, os nós gerados inicialmente sofrerão uma deformação, ou seja, um deslocamento entre os próprios nós. O solver irá interpretar estes deslocamentos, tratando cada nó como um vetor, e a partir daí, cria-se uma matriz que por sua vez, indica qual a tensão gerada em cada nó que foi deslocado, em função da carga aplicada.

\subsubsection{Entendendo a teoria FEA}

As condições de contorno são especificadas de acordo como tipo de vinculação do problema, obedecendo as regras da mecânica dos sólidos e da resultante do vetor das forças atuantes. A análise estrutural FEA, deve satisfazer os seguintes requisitos [13]:

- $\quad$ Obter equilíbrio entre: Forças e Momentos;

- $\quad$ Relacionar de forma compatível: Deformação x Deslocamento;

- Relacionar em forma de regra constitutiva: Tensão x Deformação. 
As condições acima, são usadas para gerar um sistema de equações, em que os Deslocamentos são desconhecidos.

\subsubsection{Métricas da análise FEA}

Para simular com precisão, acuracidade e eficácia a complexidade dos fenômenos físicos do mundo real, e por consequência tratar seus efeitos nos projetos, há que se considerar:

- Compatibilidade: Correlação dos deslocamentos dos "nós" externos, fazendo uma solução convergente com a deformação dos elementos;

- Relação "Força/Deslocamento" se estabelece entre: "Elemento end force" e "Elemento end deformation" e também entre as "Forças Nodais e Deslocamentos";

- Equilíbrio imposto entre: Forças Internas e Externas dos Nós.

\subsubsection{Equação constitutiva reduzida}

A tensão em um ponto tem que ser representada por um tensor para poder expressar o vetor força em qualquer direção. Para o estudo do estado de tensões no interior do corpo deformado, isola-se um elemento infinitesimal de um volume de dimensões : $\mathrm{x}, \mathrm{y}, \mathrm{z}$, conforme ilustrado na Figura 3 [10].

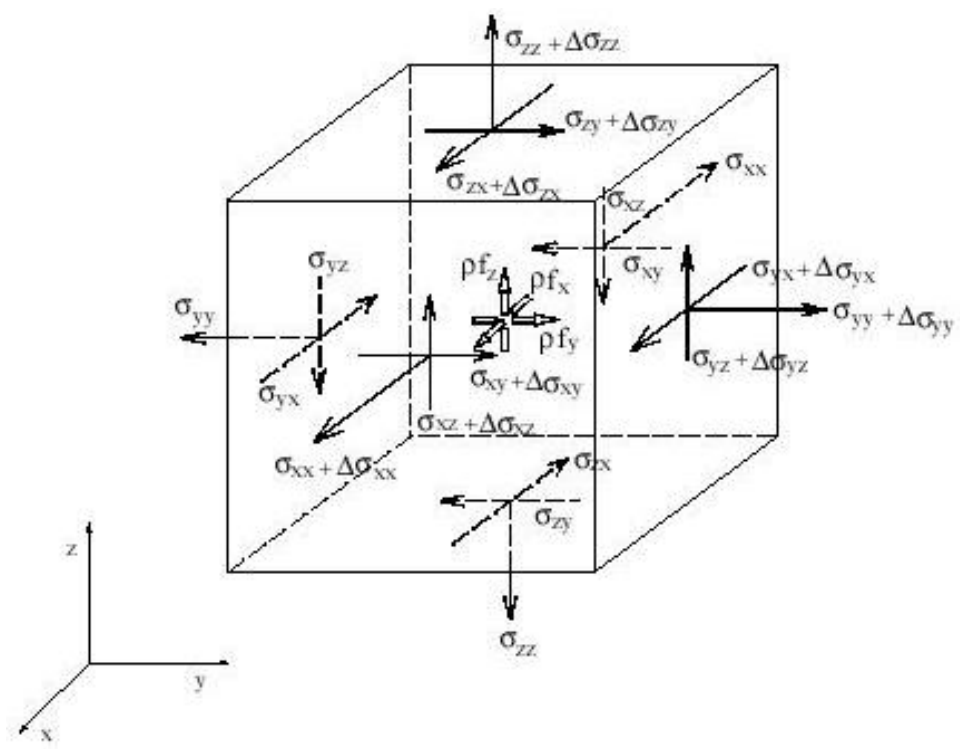

Figura 3 - Estado de tensões em um elemento infinitesimal [10]

A matriz de rigidez [K] é usada para relacionar FORÇA NODAL para DESLOCAMENTO NODAL.

Sendo os $\mathrm{K}_{\mathrm{ij}}$ os coeficientes de influência de rigidez (relaciona a força da constraint no DOF

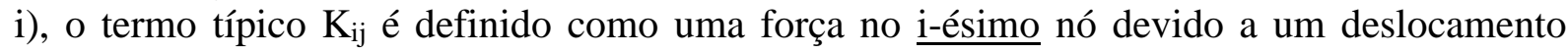
unitário no j-ésimo nó, sendo os demais deslocamentos nulos.

\subsubsection{Passos para a analise FEA}

A analise FEA pressupõe algumas etapas para a correta aplicação das condições de contorno de acordo com Figura 4, quais sejam: Modelamento geométrico, Definir 
simulação, Modelo de elementos finitos, Solver, Avaliar resultados e Otimização [9] [11].

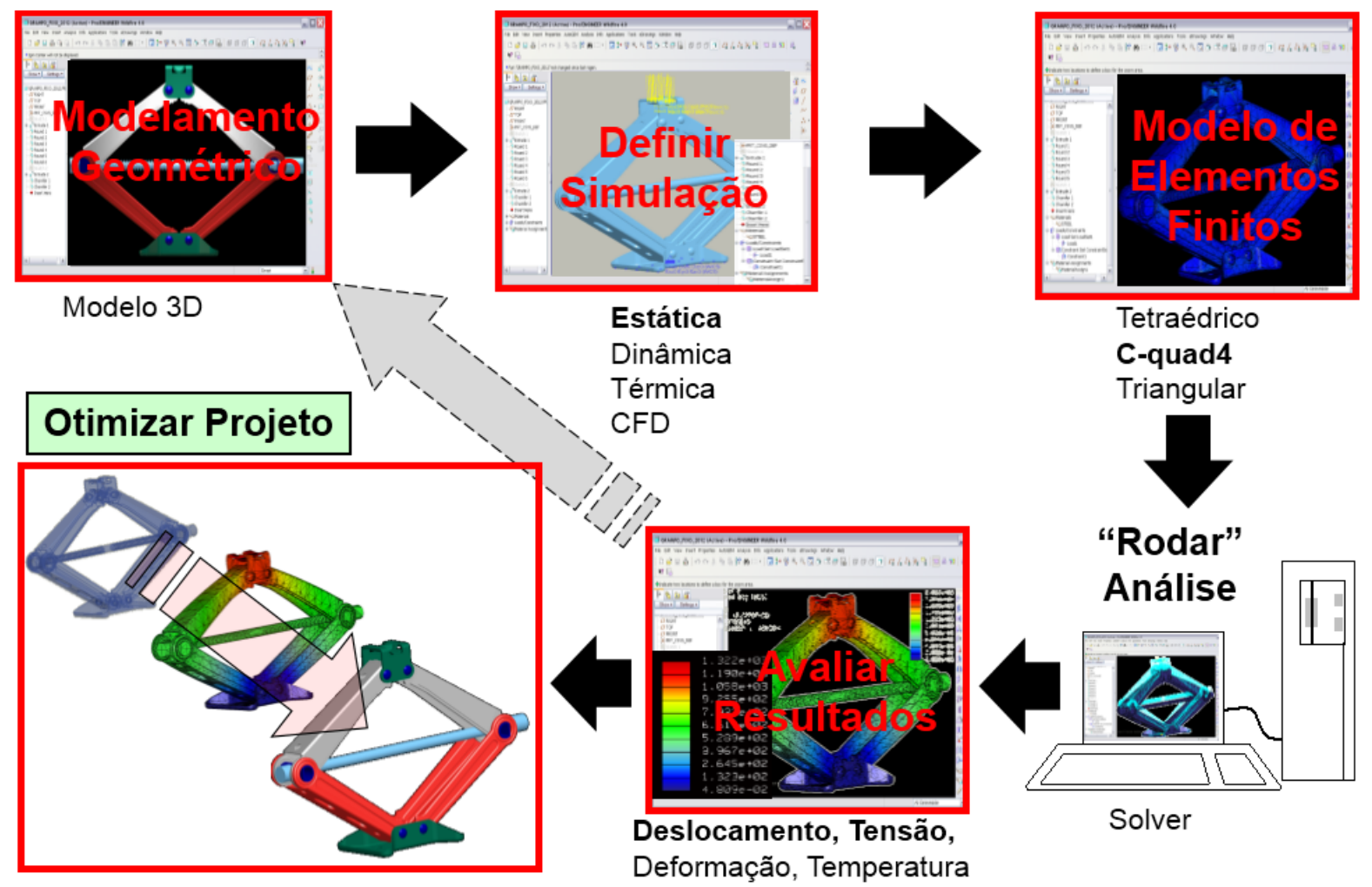

Figura 4 - Topologia computacional da analise FEA

\subsection{ESTUDO DE CASO: MACACO MECÂNICO TIPO SANFONA}

Inicialmente foi criado o modelo do macaco baseado em produtos existentes, para facilitar o estudo e reduzir a complexidade para a construção do protótipo. Cada componente foi modelado no software CREO 2.0 dentro de um ambiente CAD 3D. Visando simplificar a simulação do modelo virtual, alguns componentes como fuso, arraste e rolamento, foram suprimidos por não serem os objetos de estudo durante um teste de compressão, pois, quando o macaco mecânico é submetido à este teste, o conjunto do fuso executa a tarefa de não permitir que os braços do macaco se fechem, com isso, este conjunto foi substituído por uma barra que simule exatamente a função do fuso, ou seja, travar os braços em uma determinada posição não permitindo que o mesmo se feche (Figura 5).
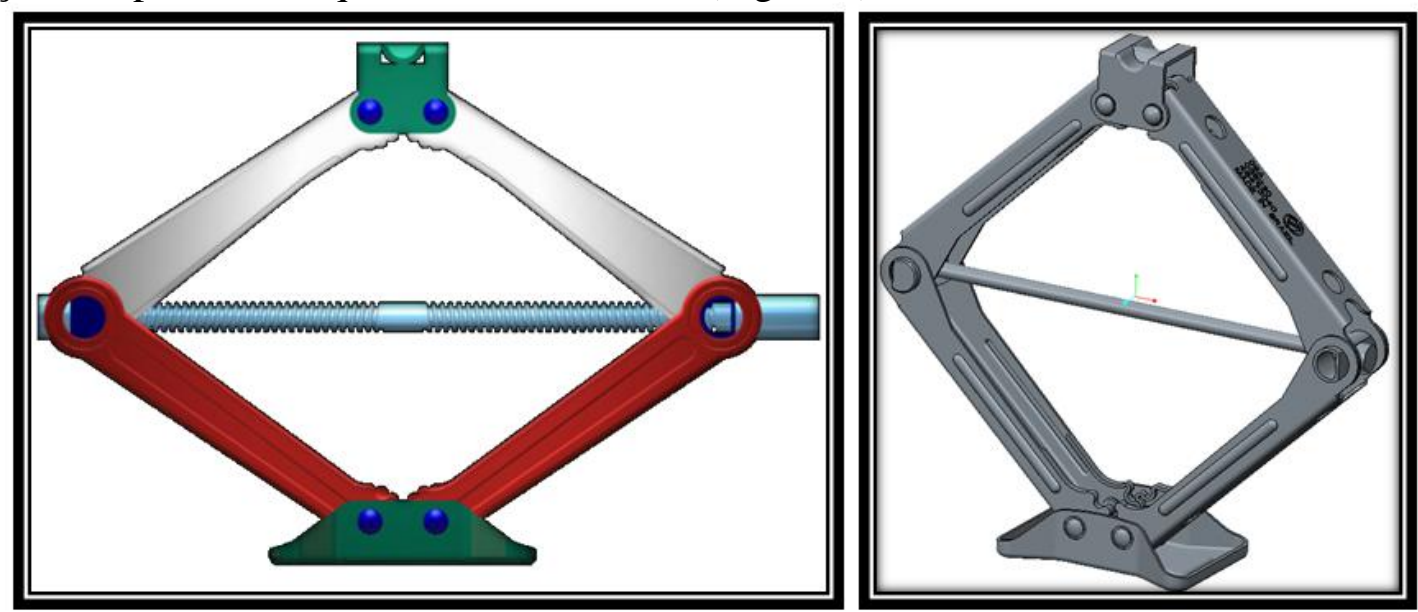

Figura 5 - Modelo matemático tridimensional 
Após concluído a vetorização do modelo matemático, iniciou-se o processo de simulação no CREO SIMULATE 2.0.

O primeiro passo da simulação foi inserir as condições de contorno (Figura 6), que irão envolver o modelo virtual, ou seja, inserir em os graus de liberdade em cada componente, o contato que cada parte exerce sobre outra, a localização onde as forças irão atuar e a intensidade da força.

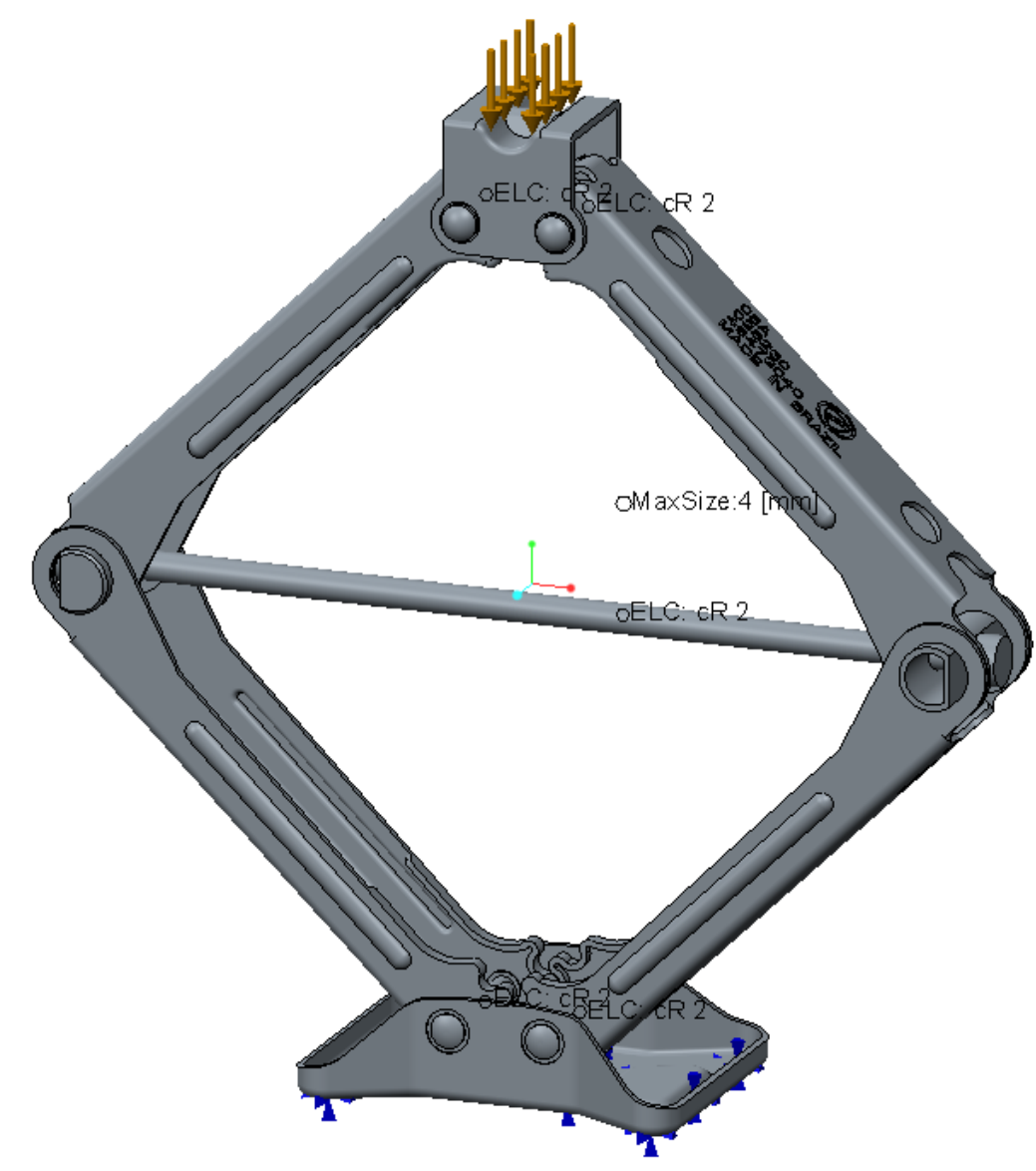

Figura 6 - Condições de contorno (boundary conditions)

Com as condições de contorno definidas, criou-se a malha que irá envolver o modelo que será a base que o solver irá utilizar para os cálculos de análise estrutural (Figura 7).

Porém, foi necessário refinar a malha por meio da adição de mais elementos em determinados lugares do modelo, onde é necessário uma precisão maior, e foi removido alguns elementos em regiões onde não era necessário um refinamento maior que o padrão.

Ao ajustar a malha para este tipo de parâmetro, o tempo de compilação do solver é reduzido para os locais em que não se deseja uma maior precisão de calculo, e nas regiões críticas, o tempo é acrescido devido ao refinamento da malha.

A lógica para definir onde seriam os locais críticos do produto, foi baseado em testes de produtos existentes, e foi rodado uma simulação com uma malha padrão, para analisar o comportamento da simulação, com as condições de contornos impostas no modelo 
matemático. Após esta análise foi refinado a malha conforme mencionado anteriormente e os resultados acham-se ilustrados conforme a Figura 8.

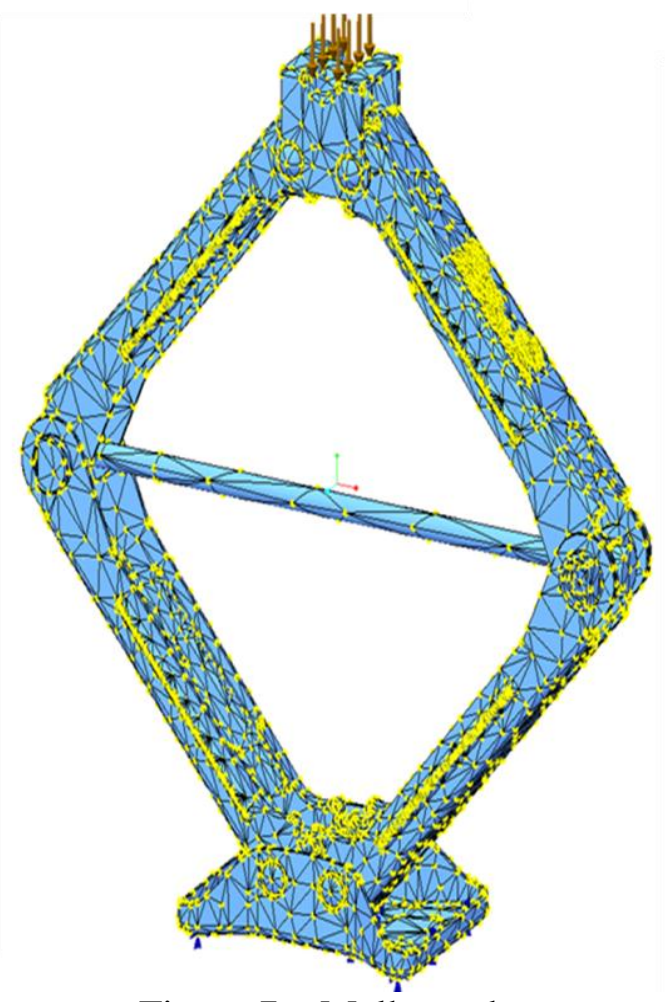

Figura 7 - Malha padrão

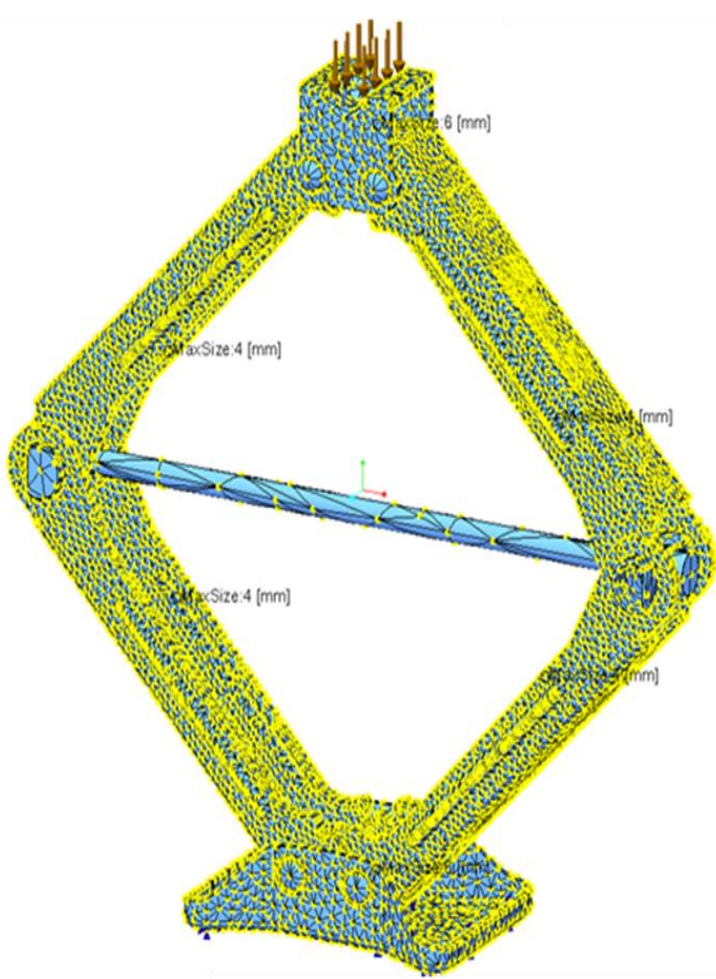

Figura 8 - Malha refinada

Definida a condição de contorno para o modelo matemático, o próximo passo foi configurar o solver para a condição de Multiple-Pass, com o grau 9 e convergência de 5\% para o algoritmo interpolador da função polinomial.

Com o solver devidamente configurado, iniciou-se a análise computacional, em que o solver iniciou os cálculos de análise estrutural. Após a finalização dos cálculos, o solver apresentou os resultados graficamente, "pintando" ou seja, indicando no modelo matemático os deslocamentos $(\Delta \mathrm{l})$ (Figura 9) e as tensões $(\sigma)$ (Figura 10).

A Figura 9 ilustra o deslocamento de $2 \mathrm{~mm}$, sofrido pelo macaco devido a carga de $2500 \mathrm{~kg}$.
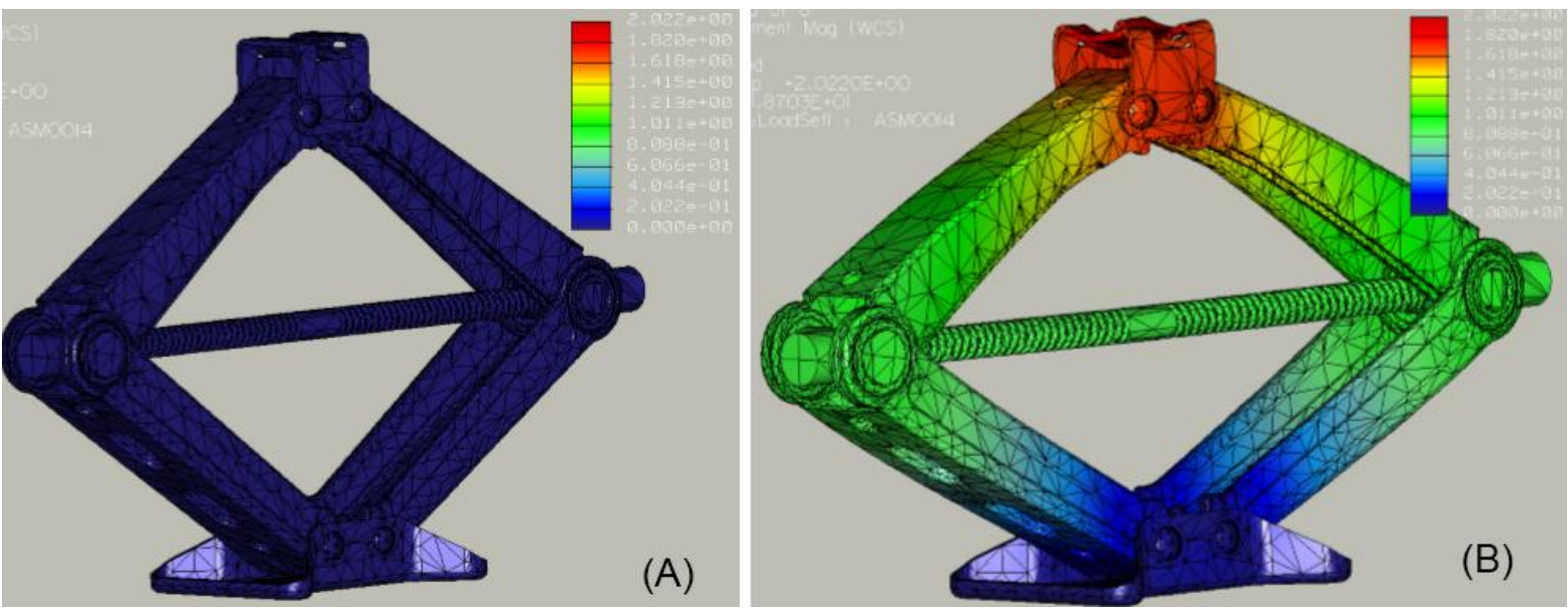

Figura 9 - Deslocamentos ( $\Delta$ l): (A) Inicial, (B) Deslocado 
A Figura 10 ilustra as tensões de $362 \mathrm{MPa}$ sofridas pelo macaco devido ao deslocamento. Percebe-se uma maior concentração de tensões nas regiões evidenciadas pelas bases superior e inferior, fuso roscado e mancal.

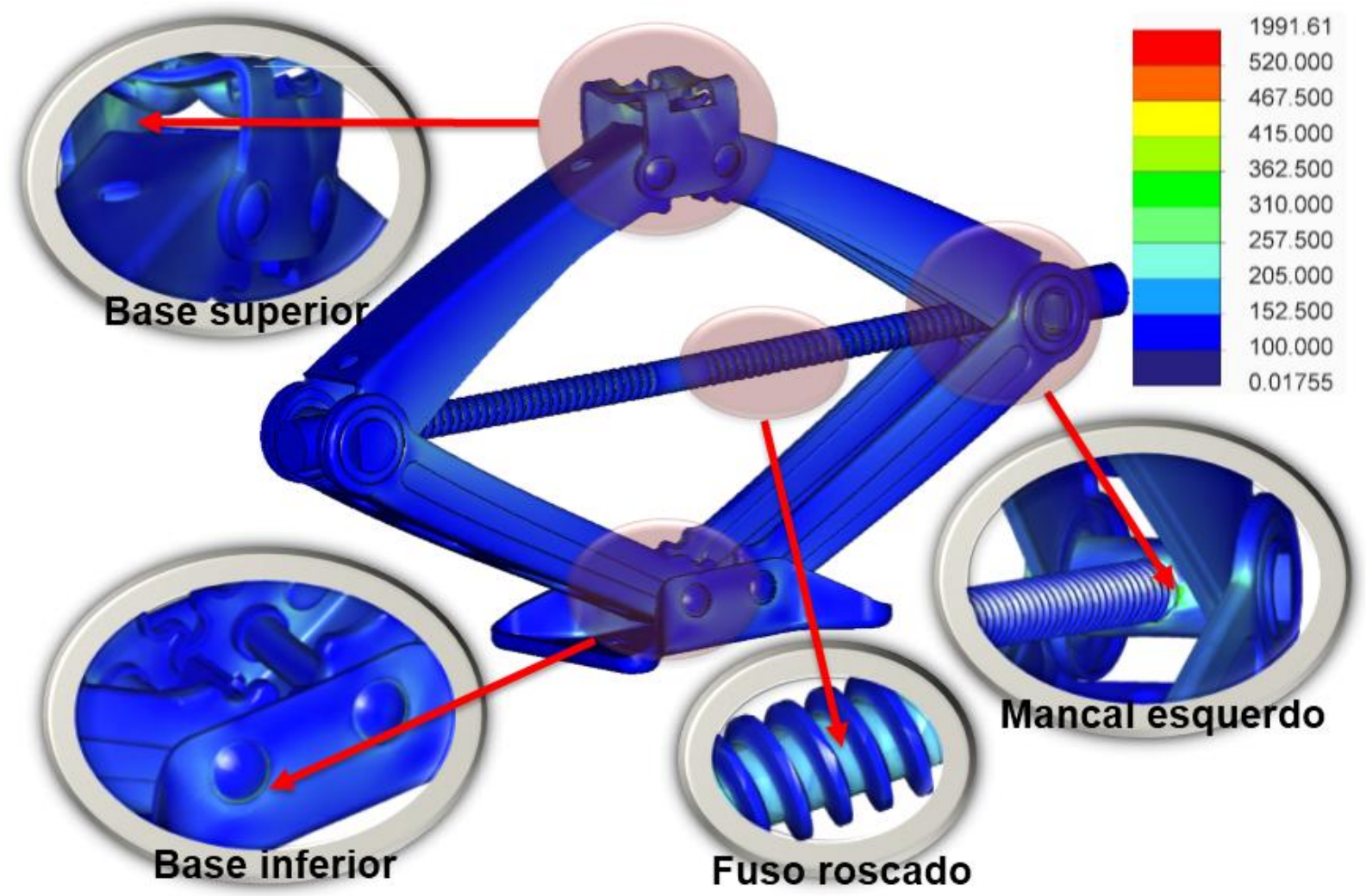

Figura 10 - Tensões $(\sigma)$ de von Mises

Com a análise estrutural finalizada, o próximo passo foi construir um protótipo e iniciar o teste de compressão para compara-lo com a análise estrutural. Pelo fato de que o objeto de estudo do Macaco mecânico eram os braços, o protótipo foi fiel a condição dos braços, porem para a base, foi utilizado um componente padrão de fabrica, que está superdimensionado para a condição de teste em que irá ser submetida, ou seja, não haverá problemas com a base que possa prejudicar o teste do macaco. A Figura 11 ilustra o protótipo manufaturado para o teste.

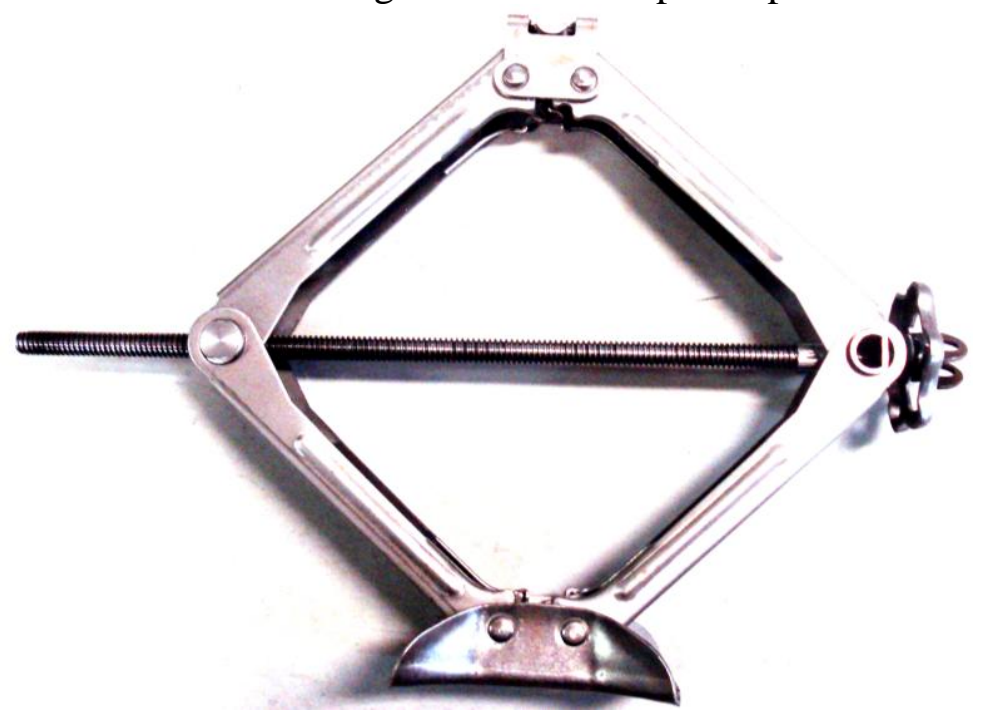

Figura 11 - Protótipo confeccionado para o teste 
Com o protótipo finalizado, realizou-se o teste de compressão com uma carga acima de 2.000 kg para verificar a resistência dos braços.

Conforme especificado no início do projeto, a carga que o produto deve suportar é $2.000 \mathrm{~kg}$ para validar o teste. O aparelho utilizado para realizar este tipo de teste foi a EMIC DL10.000, que suporta uma carga de $100 \mathrm{kN}$. A maquina registra a força e o deslocamento do objeto em teste, e emite um gráfico indicando o comportamento do teste. A Figura 12 ilustra o resultado do teste de compressão.
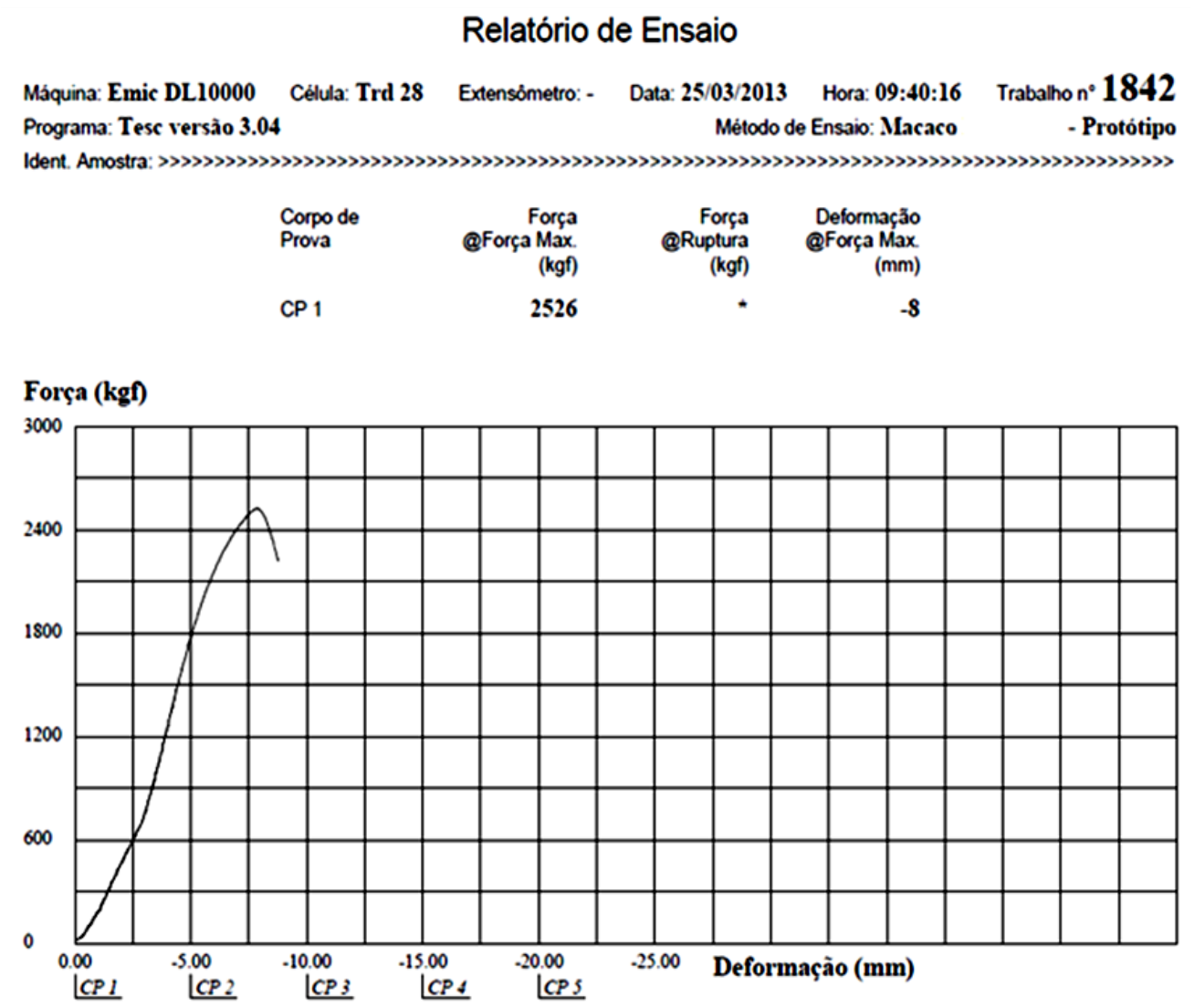

Figura 12 - Gráfico emitido pela máquina EMIC DL-1000

O resultado do teste demonstrou que o protótipo suportou $2.500 \mathrm{~kg}$ de carga, ou seja, está superior ao requisitado como dado de entrada para o projeto.

Com isto pode-se comparar com a simulação e verificar se o modelo matemático está condizente com a realidade, ou seja, verificar se é possível confiar em uma análise virtual para reduzir o tempo de projeto e desenvolver um produto com uma mínima perda de material.

Também foi gerado no ambiente de simulação, uma abordagem orientada ao estudo tomográfico com evidencias as iso surfaces.

Desta forma, fica fácil a localização da parte da peça que ocorrerá maior tensão, e assim, o engenheiro pode de forma preventiva, melhorar a geometria nesta região, tornando-a mais robusta. Também é possível gerar uma imagem tomográfica orientada ao estudo de translação (deslocamento), desta forma, é possível observar as regiões que têm maiores variações dimensionais. 
Neste trabalho, gerou-se a tomografia virtual em forma de iso surfaces, somente orientada aos aspectos de tensões de von Mises, e que está ilustrado na Figura 13.

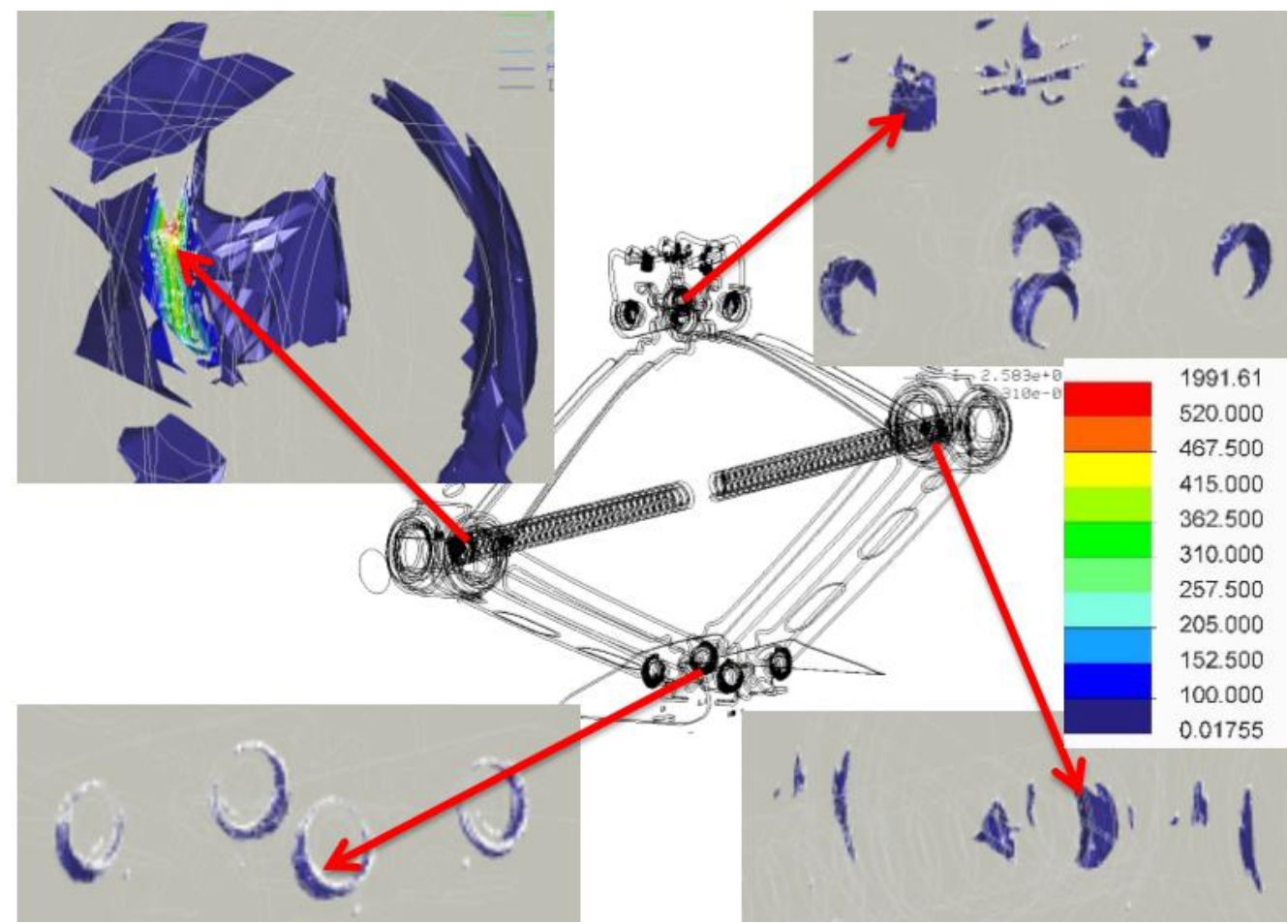

Figura 13 - Tomografia virtual evidenciando as tensões de von Mises

Como sugestão para futuros trabalhos, considerando os aspectos de robustez estrutural aliado aos resultados dos testes de laboratório, aponta-se para um modelo de relacionamento de "causa e efeito", em que o resultado da simulação servirá de base para consolidar a teoria matemática, ao mesmo tempo em que o experimento físico dará credibilidade a teoria e a simulação, estabelecendo que a simulação deve fazer parte integrante do projeto (Figura 14).

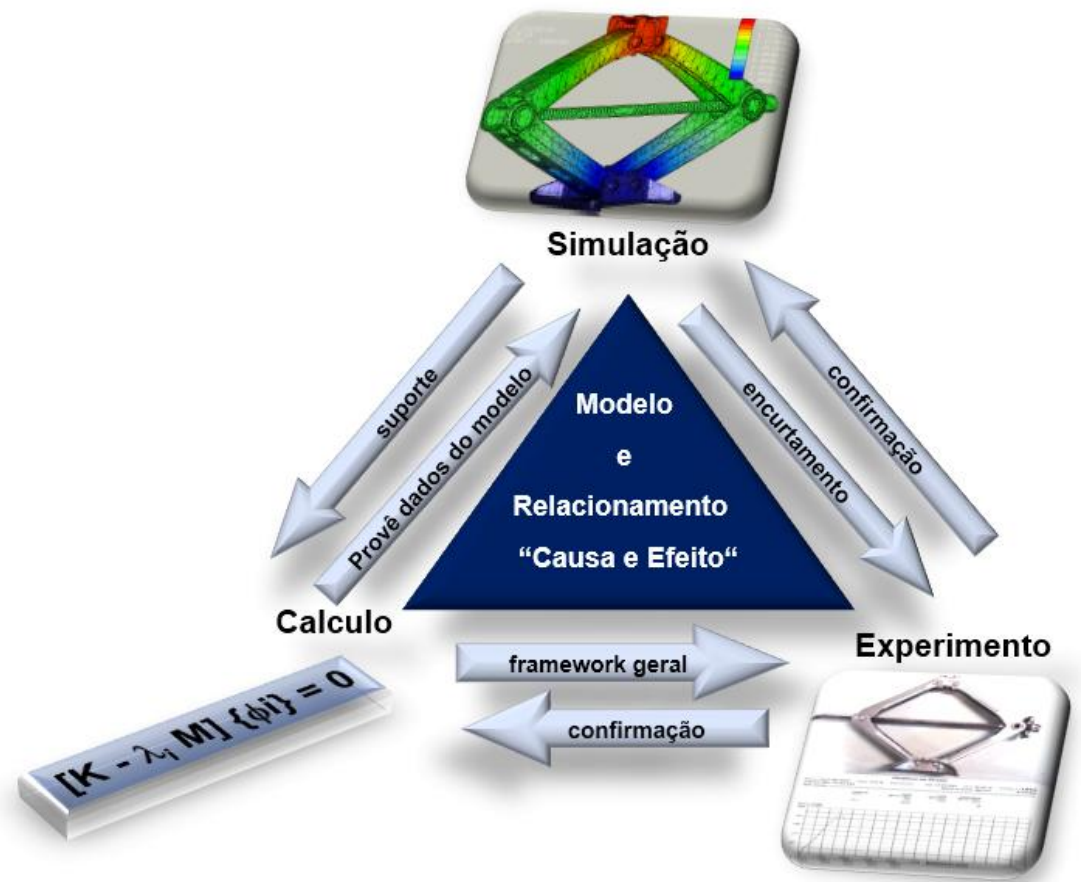

Figura 14 - Modelo e relacionamento "Causa e Efeito" 


\subsection{BULK DATA}

Foram realizadas analises estruturais lineares no macaco mecânico, para obtenção de resultados de tensões e seus devidos carregamentos inerciais e pressões advindas do processo de combustão automotiva, simulando as condições reais de funcionamento.

Para esta analise, utilizou-se um processador Intel Xeon W3565, 3.2 GHz, 64 bits, $10 \mathrm{~GB}$ RAM e disco rígido de 3,5 TB e 4 GB de swap_space, além de:

- Tempo de processamento total

- Espaço em disco requisitado

$$
\begin{aligned}
& =2: 10 \mathrm{hs}, \text { incluindo Remesh } \\
& =1392 \mathrm{MB} \\
& =55092 \\
& =89697 \\
& =126718
\end{aligned}
$$

- No. de Elementos Edges

Quanto as condições de contorno, utilizou-se um modelo matemático 3D gerado no CREO 2.0, para atender as condições de contorno iniciais. Posteriormente, adentrou-se ao módulo CAE que está encapsulado no aplicativo CREO, denominado agora de CREO Simulate.

\subsubsection{Margem de segurança}

Para o calculo da margem de segurança, a seguinte fórmula foi aplicada:

Margem de Segurança $=\left(\sigma_{\text {esc }} / \sigma\right.$ calculado $)-1=[* 100 \mathrm{p} / \%]$

1.5.2. Dados do material

Tabela 1 - Características físicas do material NBR-6656-380

\begin{tabular}{|c|c|c|c|c|c|}
\hline Material & $\begin{array}{c}\mathrm{E} \\
{[\mathrm{GPa}]}\end{array}$ & $v$ & $\begin{array}{c}\rho \\
{[\mathrm{g} / \mathrm{cc}]}\end{array}$ & $\begin{array}{c}\sigma_{\text {rup }} \\
{[\mathrm{MPa}]}\end{array}$ & $\begin{array}{c}\sigma_{\text {esc }} \\
{[\mathrm{MPa}]}\end{array}$ \\
\hline NBR6656-LNE-500 & 205 & 0.3 & 7.85 & 630 & $\begin{array}{c}380 \ldots .520 \\
(450)\end{array}$ \\
\hline
\end{tabular}

Em que:

E - módulo de elasticidade

$v$ - coeficiente de Poisson

$\rho$ - densidade

$\sigma_{\text {rup }}$ - tensão de ruptura

$\sigma_{\text {esc }}-$ tensão limite de escoamento

\section{CONCLUSÂO}

O resultado da simulação indicou que o macaco mecânico submetido a uma carga de $2.500 \mathrm{~kg}$, proporcionou um deslocamento máximo de $2 \mathrm{~mm}$, considerando todo o conjunto mecânico. $O$ teste pratico indicou um deslocamento de $8 \mathrm{~mm}$, sendo que esta divergência foi devido a folgas no fuso roscado, mancais e pinos, não sendo representativos para o foco da análise. Este deslocamento gerou tensões resultantes máximas de $362 \mathrm{MPa}$, distribuídas nas regiões das bases superior e inferior, mancais, região central do eixo roscado e braços. Uma 
vez que o material NBR6656-LNE-500 suporta tensões na faixa limite de escoamento de 380 - $520 \mathrm{MPA}$, e considerando então uma tensão média de $450 \mathrm{MPa}$, conclui-se que o resultado da simulação virtual corresponde a uma margem de segurança de $25 \%$, em relação a tensão de escoamento do material. Assim, a simulação indica que o limite máximo de carga que os braços suportam, na melhor condição de material será de $2500 \mathrm{~kg}$. O teste prático indicou que os braços do macaco suportaram uma carga de $2526 \mathrm{~kg}$, ou seja, convergiu com o resultado da simulação com uma divergência de $1.5 \%$, o que é perfeitamente previsto. Visto isto, conseguiu-se validar um processo de simulação virtual utilizando os argumentos da mecânica dos sólidos, por meio da técnica FEA com o protótipo físico, construído especificamente para convalidar a prova do erro. Para futuros trabalhos, indica-se uma melhor acuracidade no momento da imposição das condições de contorno, mais especificamente com relação a analise de contato de um macaco mecânico tipo sanfona.

\section{REFERÊNCIAS}

[1] Rozenfeld, H., Forcellini, F.A., Amaral, D.C., Toledo, J.C., Silva, S.L., Alliprandini, D.H., Scalice, R.K., Gestão de Desenvolvimento de Produtos: Uma referência para a Melhoria do Processo, Saraiva, São Paulo, 2006

[2] Alves Filho, A., Elementos Finitos - A Base da Tecnologia CAE, Editora Erica, $1^{\circ}$ Edição, São Paulo, 2000

[3] Normas técnicas Brasileiras, ABNT NBR 6656, Segunda Edição, válida a partir de $28 / 05 / 2008$

[4]Pahl, G., Beitz, W., Feldhusen, J., Grote, K.-H., Projeto na Engenharia, $1^{\text {a }}$ ed., Edgard Blücher, São Paulo, 2005

[5] Ehrlenspiel, K., Kiewert, A., Lindemann, U., Cost-Efficient Design, ASME Press, ISBN 0-7918-0250-7, New York, 2007

[6] Back, N., Ogliari, A., Dias, A., Da Silva, J.C., Projeto Integrado de Produtos: Planejamento, Concepção e Modelagem, ISBN: 9788520422083, Editora Manole, 2008

[7] Camargo, R., CAE/CAD/CAM "Uma Ferramenta para Otimização de Projetos de Cames, Recursos e Aplicações de Cálculos pelo Método dos Elementos Finitos", UNIMEP, 1990

[8] Timoshenko,S.P., Mecânica dos Sólidos Vol. 1/2, Editora LTC, RJ, 1998

[9] MacNeal, R., MSC/NASTRAN for Window: Finite Element Modeling, MacNeal Schwendler Corporation, San Diego / Califórnia, 1997

[10] Fonseca, J.S.O, Selk, C.A.C., Pereira, L.T.V., Marczak, R.J., Alves, D.B., Luersen, M.A., Ferramentas de Simulação em Mecânica: Elementos Finitos, UFRGS, 2002

[11] Camargo, R., Topologia de Projeto Robusto aplicando o método dos Elementos Finitos, Revista Ciência e Tecnologia, v. VII, p. 13-29, 2004

[12] Zienkiewicz, O. C. e Taylor, R. L., Finite Element Method- Basic Formulation and Linear Problems, Vol.1, McGraw-Hill Co., New York, 1989

[13] Bathe, K. J.: Finite Element Procedures, Prentice-Hall, Englewood Cliffs, 1995 